\title{
Give us a call, says NASA
}

Alex Dorozynski reports from Paris on the Viking symposium held there last week

NASA's next Mars package will be launched from Cape Kennedy in January 1984. It will carry a roving laboratory capable of covering at least $100 \mathrm{~km}$ and perhaps as much as $1,000 \mathrm{~km}$ of the planet. The orbiting satellite will contain 'penetrators', to be implanted at and to transmit information from selected locations, as well as remote sensing and transmission equipment. Lodged several metres into the Martian soils, the penetrators will record seismic activity and will try to determine the chemical composition of Martian soil below the surface. No attempt will be made to bring soil samples back to Earth; the earliest date for a rational sample return mission, rather than an indiscriminate 'grab sample' attempt, is 1988 .

This schedule is not an official one, but it sums up the consensus of opinion at last week's symposium. The symposium involved senior scientific and management personnel of the Viking programme, the European Space Agency and the French National Centre of Space Studies. The Viking team will now tour several European countries, including the Soviet Union, to inform intercsted scientists of the latest Viking results and to emphasise that NASA planetary exploration programmes are open to international participation.

According to the Viking chief project scicntist, Dr Gerald A. Soffes, no part of the schedule is in the approved stage. But the outlook is favourable indeed. By any standards - science, technology, public appeal--Viking has been an outstanding success, and data is still pouring in from the two landers and the two orbiters. These will all be kept at work for at least another full year. One single orbiter may continue to relay information from both landers, while the other will be switched over to different orbits in order to roam the surface of the red planet with its remote sensing equipment.

President Carter has recently proposed an increase in NASA 'study money" for 1978 (the increase awaits Congressional approval) but the agency does not seem to want to go to Mars with another Viking just for the sake of it; rather it wishes to exploit the massive flow of data to prepare the next Viking generation. The $1979 z$ 'astronomical window' to Mars seems too close for this, so the project for early 1984 , even though it is not optimal from the energy viewpoint, has been adopted as a goal by the study team and this is already at work.

Dr Soffes and his colleagues made a point of inviting non-American guest scientists to participate in the study of Viking data and the elaboration of future missions. According to A. Thomas Young, the Viking missions' operations manager, participation would include the elaboration of scientific experiments, instrumental design, and perhaps even the loading on board of an experimental package-provided of course it fits into the overall package. Dr Young suggested that the first proposals be made to the NASA by midMay this year, so that planning of the still-hypothetical 1984 mission could start early in October.

Meanwhile all Viking data is being made available to interested scientists. Major reports have been published in three issues of Science; these have not apparently been found sufficiently detailed and complete by some specialists, so a thorough review is now being prepared, including most recent data, for publication in the Journal of Geophysical Research in September.

Dr Soffes also hopes for an international Viking conference similar to the one that followed the Mariner mission, but, he says, "it is not easy to put together or to know when it should happen." In the meantime limited discussions on specific aspects of Viking results will be held during other meetings. These will take place, for example, at the lunar samples meeting in Houston in March, the meeting in Kioto in June of the International Biological Society for the Study of the Origin of Life, and the pulsar meeting in Tel Aviv, also in June. Scientists are also being encouraged to contact NASA directly concerning aspects of Viking in which they are particularly interested.

New data is coming in so rapidly that publications cannot keep up without delays of six months or more, and the participants in the Viking symposium at the Palais de la Découverte in Paris were given more than enough to whet their appetites. On the menu : the Mars quake, registered during the primary mission, which took place some $50 \mathrm{~km}$ away from the landing site, and was measured between 2 and 3 on the Richter scale; the first close range photograph of Phobos, one of Mars's small moons; the decreasing atmospheric pressure, now increasing again as winter approaches in the northern hemisphere; the verification of Einstein's general theory of relativity; the phenomenon of Mars' dusts storms and the unusual erosion patterns that have been photographed and still remain a puzzle. Finally, of course, there are the biology experiments, which Dr Leslie Orgel, Head of the Viking molecular analysis team, described as the most positively negative, adding that in fact they had given no answer; Viking had landed in one of the "most desolate positions on Mars". Other sites will be explored during the next mission; but Mars conditions, or at least some of them, are now being re-created in the laboratory to find out whether earthly life forms can survive in them. As other sites may have conditions entirely different from the ones at the Viking landing sites, there is still hope for life. "We may have found that where it's red, it's dead" quipped Dr Orgel; but Mars is red all over.

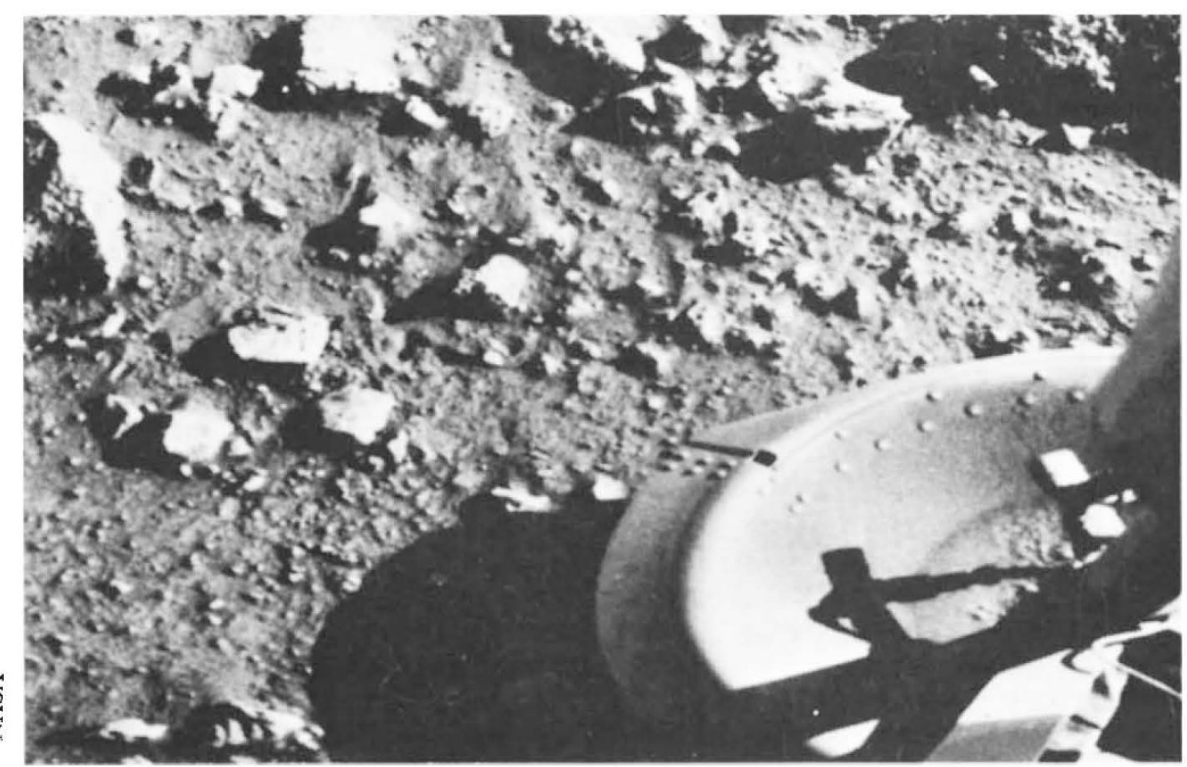

Back to 1976: a view from Mars 